\title{
Finite Element Modelling to Investigate the Mechanisms of CRUD Deposition in PWR
}

DOI:

10.1007/978-3-319-68454-3_80

\section{Document Version}

Accepted author manuscript

Link to publication record in Manchester Research Explorer

\section{Citation for published version (APA):}

Wu, J., Stevens, N., Scenini, F., Connolly, B., Banks, A., Powell, A., \& Pegg, L-J. (2017). Finite Element Modelling to Investigate the Mechanisms of CRUD Deposition in PWR. In 18th International Conference on Environmental Degradation in Nuclear Power Systems andє" Water Reactors https://doi.org/10.1007/978-3-319-68454-3_80

\section{Published in:}

18th International Conference on Environmental Degradation in Nuclear Power Systems and€" Water Reactors

\section{Citing this paper}

Please note that where the full-text provided on Manchester Research Explorer is the Author Accepted Manuscript or Proof version this may differ from the final Published version. If citing, it is advised that you check and use the publisher's definitive version.

\section{General rights}

Copyright and moral rights for the publications made accessible in the Research Explorer are retained by the authors and/or other copyright owners and it is a condition of accessing publications that users recognise and abide by the legal requirements associated with these rights.

\section{Takedown policy}

If you believe that this document breaches copyright please refer to the University of Manchester's Takedown Procedures [http://man.ac.uk/04Y6Bo] or contact uml.scholarlycommunications@manchester.ac.uk providing relevant details, so we can investigate your claim.

\section{OPEN ACCESS}




\title{
Finite Element Modelling to Investigate the Mechanisms of CRUD Deposition in PWR
}

\author{
Jiejie $\mathrm{Wu}^{1}$, Nicholas Stevens ${ }^{1}$, Fabio Scenini ${ }^{1}$, Brian Connolly ${ }^{1}$, \\ Andy Banks ${ }^{2}$, Andrew Powell ${ }^{2}$, and Lara-Jane Pegg ${ }^{2}$ \\ 1 The University of Manchester, UK \\ 2 Rolls-Royce Plc., UK \\ jiejie.wu@manchester.ac.uk
}

\begin{abstract}
Corrosion Related Unidentified Deposition (CRUD) in PWR may cause severe issues, such as Tube Support Plate (TSP) blockage, fuel cladding cracking, and subsequently increased radiation doses for workers. The primary objective of this work is to develop an all-inclusive deposition model, which will reproduce the morphology and elucidate the contributing electrokinetic mechanisms. In this paper the development and verification of a model of the streaming current linking the potential distribution and the fluid flow behaviour using the Finite Element Method (FEM) is presented. In the model, coupled anodic and cathodic regions were found at the inlet of a pipe restriction, associated with a region of recirculating flow following the front facing step (FFS). The corresponding current densities and overpotential at the metal/solution interface were calculated. The coupled anode and cathode may explain the observed deposition process - generating deposits at the front facing step first, followed by a region free of deposits and then repeating ripples of deposited material. At the restriction outlet, a cathode was found which balances the current loops. In this paper, the simulated initiation and propagation processes of the electrokinetic deposition are presented.
\end{abstract}

Keywords: CRUD, Electrokinetic deposition, Streaming currents, Multi-physics modelling, Finite Element Method

\section{Introduction}

CRUD was first observed in one of the earliest Canadian reactors in 1950's [1]. It was found that corrosion products from structural components in nuclear plants tend to deposit in different locations, such as restrictions in steam generators and instrumentation [2], and fuel cladding [3], causing operational difficulties. Primary flow rate variations due to the deposit formation were observed in some French and US plants [4].

CRUD mainly consists of magnetite $\left(\mathrm{Fe}_{3} \mathrm{O}_{4}\right)$ and nickel ferrite $\left(\mathrm{NiFe}_{2} \mathrm{O}_{4}\right)$ [5]. There are two main kinds of deposits: (a) hard and adherent deposits due to the precipitation from dissolved cations from solution, and (b) porous and loose deposits generated from particulate species [6,7]. This paper will only focus on the former deposition which is driven by an electrokinetic mechanism. In order to study the behaviour of this deposition, experimental research has been performed by Guillodo et al. [8], who proposed an electrokinetic mechanism of the deposit generation based on the work of Robertson [9] and Woolsey [10]. In Guillodo's work, the deposition was observed at the entrance to a $6 \mathrm{~mm}$ diameter restriction, and along the annulus close to the entrance, in high flow rate and high temperature primary coolant condition [4]. Work on CRUD deposition in micro-orifices with very high flow velocities has been performed by Scenini et al. [11]. The electrochemical potential 
distribution through the annulus of a test has been measured [12] and the anodic and cathodic behaviour of the current component at the front face of an orifice where the CRUD is known to deposit has been investigated [13].

The modelling of deposition is not widely studied. Some simulation research of the particulate deposition can be found in some references [14-16]. However, the numerical simulation of the electrokinetic deposition is not often seen. This paper aims to simulate the initiation and propagation processes of the electrokinetic deposition in pipe restrictions, looking at the current loops created by an electrokinetic current arising from flow over a charged surface in the region of a change in the internal geometry which acts to interrupt the flow profile. The polarization created by these loops is studied and, under the assumption that anodic polarization causes enhanced deposition, a hypothesis is proposed to explain the observed 'rippled' geometry reported for CRUD deposition.

\section{Electrokinetic Mechanism}

When a charged solid wall (metal) surface is exposed to an electrolyte, an Electrical Double Layer (EDL) with excess charge will be formed which consists of two layers; the Helmholtz layer and the diffuse layer as shown in Fig. 1. The Helmholtz layer is immobile and adherent to the wall surface. A slip plane can be found between these two layers, where the diffuse layer starts to move. The excess charge displacement in the diffuse layer caused by the fluid flow velocity generates a streaming current, $I_{s}$, along the wall surface as shown in Fig. 2a. The potential at the slip plane (Fig. 2b) with respect to the value in the bulk solution is known as zeta $(\zeta)$ potential [17]. Where the zeta potential value is negative, the wall surface is negatively charged and the EDL has excess positive charge.

When the fluid flows over sharp geometric disturbances as shown in Fig. 2c, the streaming current will change as the flow velocity changes. Where the solution resistivity, $\rho_{s}$, is much higher than the polarization resistance of the metal/solution interface, $R_{p o l}$, a wall current, $I_{w}$, contributes to a streaming current increase, $\delta I_{s}$, at an accelerating region as an anodic current and conducts away the majority of the streaming current to the wall at a decelerating region as a cathodic current (Fig. $2 \mathrm{~b}$ and c). The portion of the current loop in the metal is greater than that in the solution due to the greater conductivity of the metal. Therefore, the current from the bulk is negligible under the condition $\rho_{s}$ >> $R_{\text {pol }}$. Fig. 2 c also shows that the wall current passing through the interface and coupling with the streaming current generates current loops between the solution and wall.

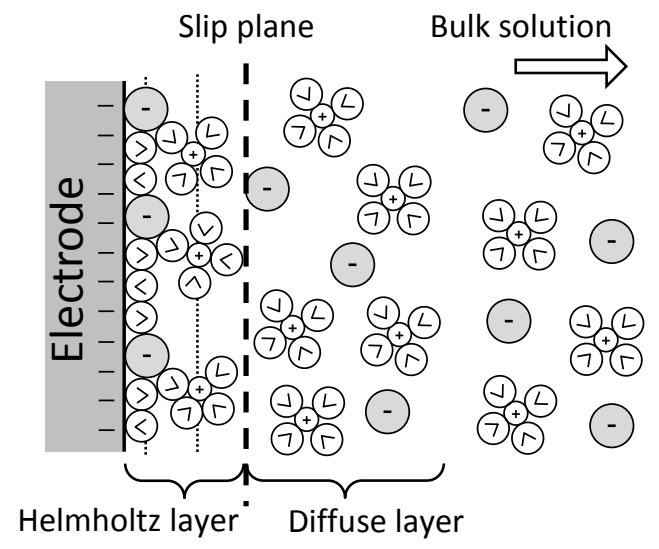

Fig. 1 Electrical Double Layer (EDL) [17][18][19] 
a

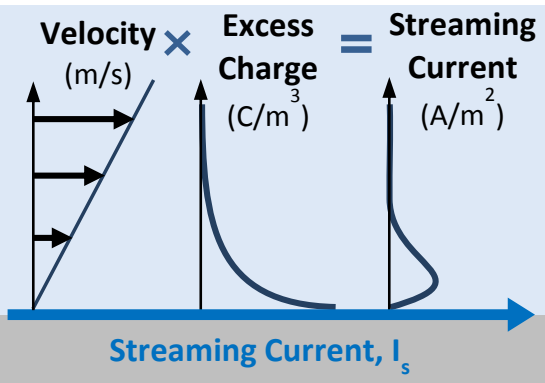

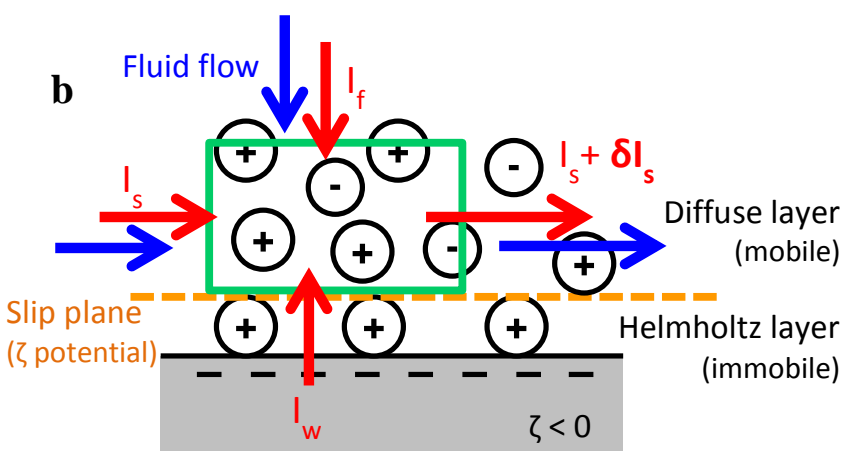

Decelerating Flow

c Accelerating Flow

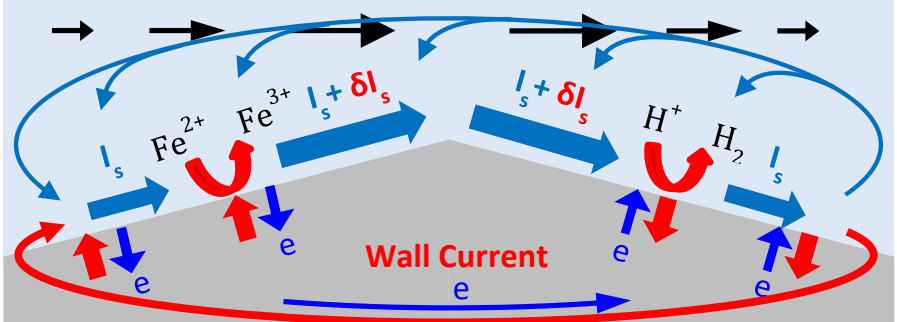

Fig. 2 Streaming current $(\zeta<0)$ a Generation b Control volume [20] $\mathbf{c}$ Variation over sharp disturbances $\left(\rho_{\mathrm{s}}>\mathrm{R}_{\mathrm{pol}}\right)$

Fig. 3a shows the geometry step used in this work for a tube restriction (grey - metal; blue arrows fluid flow) and Fig. 3b-d (red arrows - electric current) are the axisymmetric cross section expansions of the dashed box from Fig. 3a. The geometry step face at the inlet of the restriction is called the Front Facing Step (FFS) as shown in Fig. 3a. At the restriction, the accelerating fluid flow at the FFS generates an anode and the decelerating fluid in the flow recirculation zone adjacent to the step forms a cathode, as shown in Fig. 3b. The streaming current in the EDL links the anode and the cathode generating a current loop between the wall and the solution. The anodic reaction in this model is assumed to be the oxidation of iron generating magnetite which will modify the local solubility [8]. Therefore, initial deposit forms at this anodic region (Fig. 3c). After this, a new current loop is found following the recirculation zone due to the new accelerating and decelerating regions, which will generate a second deposit, as shown in Fig. 3d. Stages 1 to 2 schematically describe the deposition initiation process and stages 2 to 3 describe the deposition propagation.

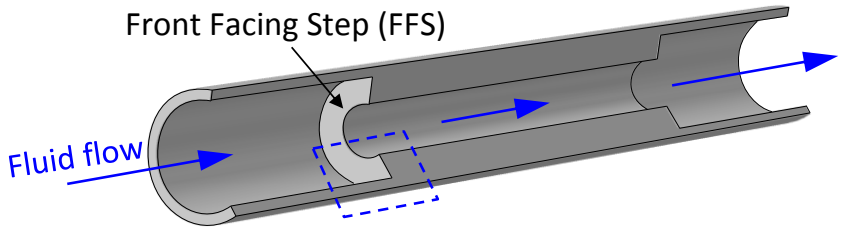

$\mathbf{b}$

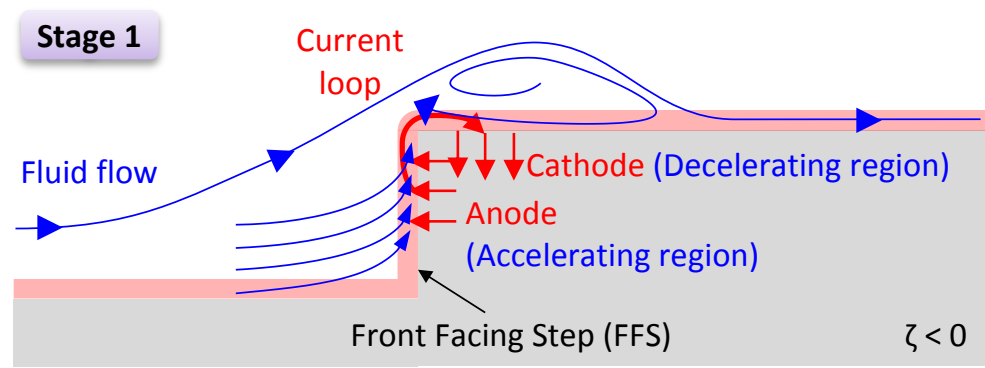

c

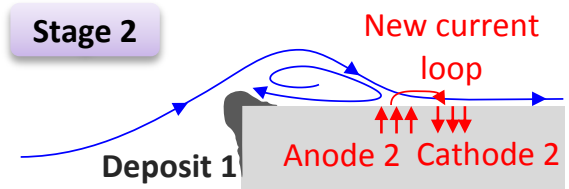

d Stage 3

New current

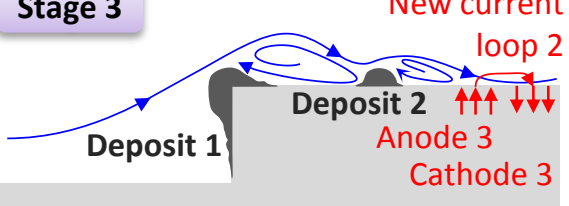

Fig. 3 Schematic plots of deposition initiation and propagation a Geometry in 3D used in the model (grey - metal; blue arrows - fluid flow) b Deposition initiation (expansion of dashed box from a; red arrows - electric current) $\mathbf{c}, \mathbf{d}$ Deposition propagation 


\section{Model Set-up}

The thickness of the EDL is solution-dependent and varies from a few nanometres to a few hundred nanometres [21,22]. In order to maximise the effect of the EDL in the electrokinetic deposition process, a geometry with a small size $(\mu \mathrm{m})$ was used in this model (small when compared to other research tests $[4,7,10])$. A $2 \mathrm{D}$ cross-section of the simple step-geometry shown in Fig. 3a, which moves from a $20 \mu \mathrm{m}$ inner diameter cylindrical tube to a restriction which is a $10 \mu \mathrm{m}$ diameter tube with $100 \mu \mathrm{m}$ length, is shown in Fig. 4a (not drawn to scale). The simulated fluid (blue in Fig. 4a) is a solution of $0.03 \mathrm{~mol} / \mathrm{m}^{3} \mathrm{NaCl}$ in water, which will be used to form excess charge in EDL, and the simulated generic metal (grey) is steel UNS G43400 (AISI 4340) with a very low surface polarization resistance $\left(\rho_{s}>R_{p o l}\right)$. The dashed box shows the most intricate and interesting area in this model. The average restriction velocities, $\overline{\boldsymbol{v}}_{\boldsymbol{r} \boldsymbol{e}}$, of 4, 20,40,60, 80, 120 and $200 \mathrm{~m} / \mathrm{s}$ were investigated.

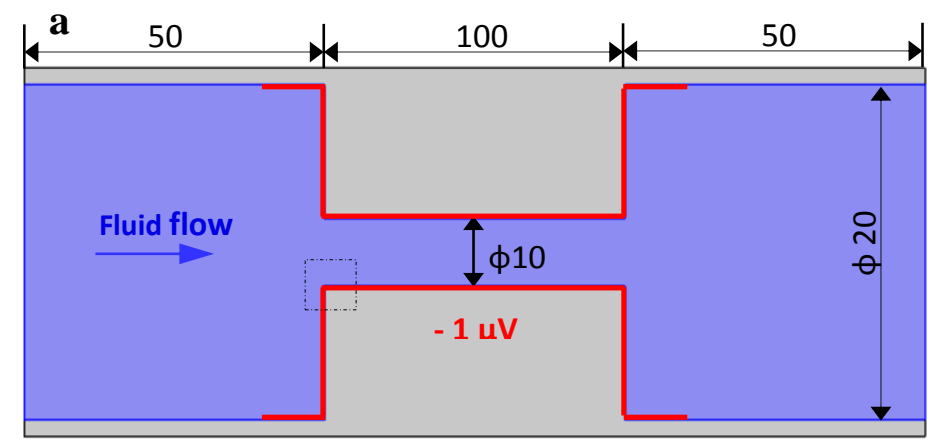

\section{b}

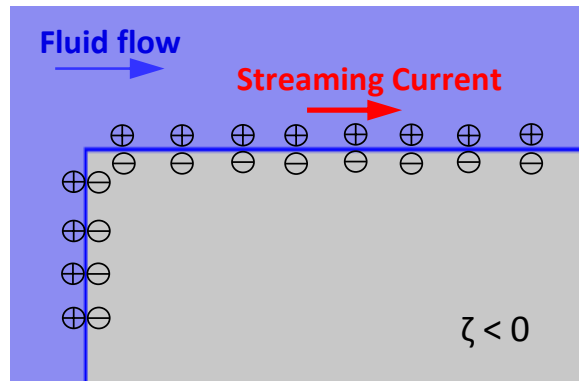

Fig. 4 a 2D cross-section of the geometry ( $\mu \mathrm{m})$ (red lines - applied electric potential; dashed box - area of interest) b Excess charge in the double layer generating streaming current

This model consists of three components: Transport of Diluted Species, Electrostatics and Electric Current. In the electrostatic module, an electric potential of $-1 \mu \mathrm{V}$ is applied along the restriction step as shown in Fig. 4a (red lines), with an electric ground applied as a boundary condition at the inlet and outlet at the beginning and end of the restriction in the $\mathrm{x}$ direction. The applied negative charge on the metal surface generates an EDL with excess positive charge in the fluid side of the interface and produces a negative $\zeta$-potential as shown in Fig. 4b. The solution flow was modelled assuming timeaveraged turbulent flow, and the velocity was multiplied by the excess charge to generate streaming currents in the near wall region (Fig. 2a) from upstream to downstream as the flow sheared the ions in the electric current module. Tafel behaviour was applied to the restriction boundary in this module to find the localised current densities.

$$
\begin{gathered}
\eta=V_{m}-V_{s} \\
j_{a}=j_{0} \exp \frac{\alpha_{a} n F \eta}{R T} \\
j_{c}=j_{0} \exp \frac{-\alpha_{c} n F \eta}{R T} \\
j=j_{a}-j_{c}
\end{gathered}
$$

In Equation (1) to (4), $\eta$ is the overpotential, $V_{m}$ is the potential of the metal and $V_{s}$ is the potential of the solution. Anodic and cathodic current densities are denoted as $j_{a}$ and $j_{c}$ respectively, while $j_{0}$ is the exchange current density, which is set equal to $10^{-6} \mathrm{~A} / \mathrm{cm}^{2}$ as referenced from reactions on steel 
surface at high temperature [23]. The anodic and cathodic transfer coefficients, $\alpha_{a}$ and $\alpha_{c}$, are arbitrarily set to 0.5 , which is a common value for simple electron-transfer reactions [19].

A few assumptions were made before the model set-up: the excess charge in the Helmholtz layer is included in the boundary condition; fluid flow is independent of the electric distribution and the velocity is not coupled to the species transport; EDL is too small to change the shape; only Tafel kinetics is applied for anodic and cathodic process; the solution conductivity is constant.

\section{Results and Discussion}

\subsection{Deposition Initiation - Stage 1}

\subsubsection{Current Path}

Fig. 5a shows the current path detail at the inlet of the restriction which is the area in the dashed box in Fig. 4. The red/black normalised arrows are the currents in the solution/metal, respectively. The large red arrows represent the streaming current in the double layer, part of which flows upstream in the opposite direction to the bulk. This is due to the fluid flow recirculation zone shown in Fig. 5b, which carries the excess charge upstream. The size of the upstream streaming current is controlled by the size of the recirculation zone, which is $9 \mu \mathrm{m}$ at an average restriction velocity of $200 \mathrm{~m} / \mathrm{s}$. This size is very close to the inner diameter of the restriction which is $10 \mu \mathrm{m}$. It should be noted that the normalised arrows in the solution and metal bulk don't represent the values of the local current which can be between six and eight orders of magnitude smaller than the streaming current along the wall surface.
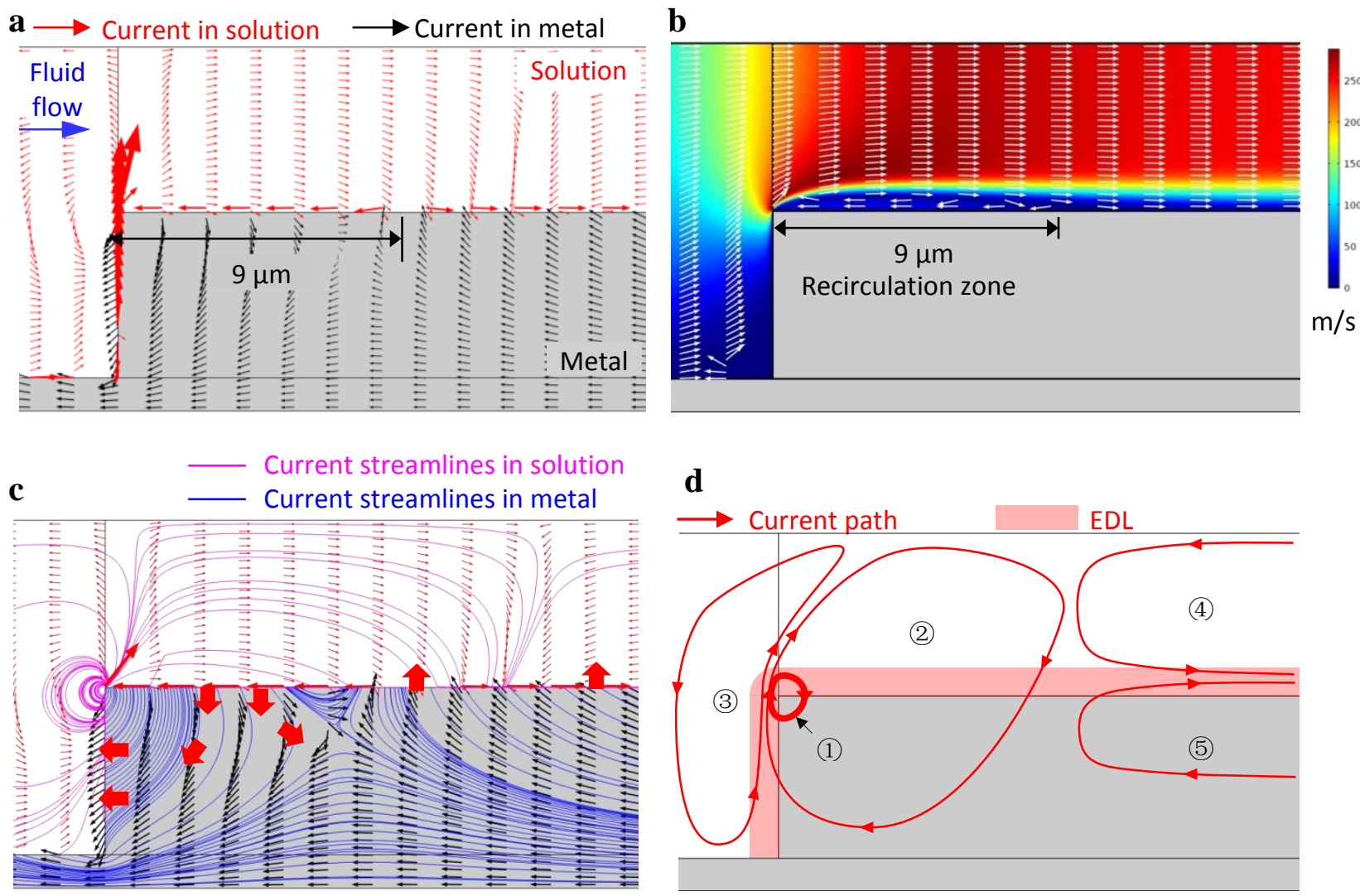

Fig. 5 Current and fluid flow at stage 1 a Current in solution and metal b Fluid flow velocity field showing a $9 \mu \mathrm{m}$ recirculation zone adjacent to the inlet, $\overline{\boldsymbol{v}}_{\boldsymbol{r} \boldsymbol{e}}=200 \mathrm{~m} / \mathrm{s}$ c Current streamlines $\mathbf{d}$ Schematic current path 
Current streamlines in both solution and metal are shown in Fig. 5c. Current is conducted into the metal adjacent to the inlet; most of the current re-joins the solution through the FFS and the rest flows back to the solution further downstream. Due to the large difference in conductivity between the metal and solution, most of the streamlines (and thus current) can be found in the metal.

Fig. $5 \mathrm{~d}$ shows the schematic current path. The most active area is located at the inlet of the restriction where the accelerating streaming current at the FFS sweeping into the restriction meets the upstream streaming current inside the restriction at the inlet. The majority is conducted into the metal generating current loops between the metal and solution passing through the metal/solution interface. The most intense current loop is located at the sharp corner as loop 1. Loop 2 shows the edge of the current between the metal and solution at this region. The rest streaming current from FFS couples with the current in the solution bulk forming loop 3. It is deformed due to the accelerating flow in this area. The remaining streaming current in the EDL moves downstream, giving two additional loops, loop 4 and 5, extending to the outlet of the restriction.

The size of the model geometry has been chosen in this case to be small to allow the different physical processes involved to all be modelled in one mesh. The concentration of the current in small areas near the sharpest features interrupting the flow, to create local pairs of anodes and cathodes, suggests that this process is a localised one which may not be strongly affected by changes to the geometry away from the wall regions such as using larger pipes, provided the local shear rate at the wall and electrical behaviour of the walls is constant.

\subsubsection{Overpotential and Normal Current Density}

Fig. 6a and b show the overpotential, $\eta=V_{m}-V_{s}$, and normal current density, $j_{\perp}=j_{a}-j_{c}$, along the restriction step from point $\mathrm{D}$ to $\mathrm{E}$ at different average restriction velocities, respectively (the same points in Fig. 6c). Overpotential between the metal and solution drives the current movement in the interface. Where $V_{m}>V_{s}$, the only way to balance the potential is to move electrons from solution to metal, which generates an anodic current. Where $V_{m}<V_{s}$, a cathodic current will be generated. Therefore, the interface exhibits anodic behaviour from point $\mathrm{D}$ to $\mathrm{A}$, with current flowing from metal to solution, and cathodic behaviour from point $\mathrm{A}$ to $\mathrm{B}$ and at point $\mathrm{C}$, with current flowing from solution to metal. The size of the cathodic region is the same as that of the recirculation zone (Fig. $5 \mathrm{~b}$ ) which is also $9 \mu \mathrm{m}$ at an average restriction velocity of $200 \mathrm{~m} / \mathrm{s}$. The extreme values of anodic and cathodic currents are located around point A (Fig. 6b) which is shown as loop 1 in Fig. 5d. Fig. 6c shows current passing through the metal/solution interface at anodes and cathodes. The main deposit generation process discussed in this work is the oxidation of ferrous ions into magnetite which is an anodic reaction $[8,10]$. Therefore, the first anode (from D to A in Fig. 6c) is assumed to be where the initial deposit is located at. It should be noted that we have termed this initial deposit as 'deposition initiation'. A second anode was found following the first cathodic region, which gives rise to the formation of a second deposit.

Overpotential and normal current density both increase with the increasing average restriction fluid flow velocities. This may be due to the high shear rate along the wall surface at high velocity, which moves more charge in the same time unit generating higher current density. More details of the dashed box of the normal current density are shown in Fig. 6b. The values of the current density and the sizes of the anodes and cathodes increase with the increasing velocities. This implies that the quantity and the size of the deposits at high velocity may be larger than those produced at low velocity in a certain velocity range. 

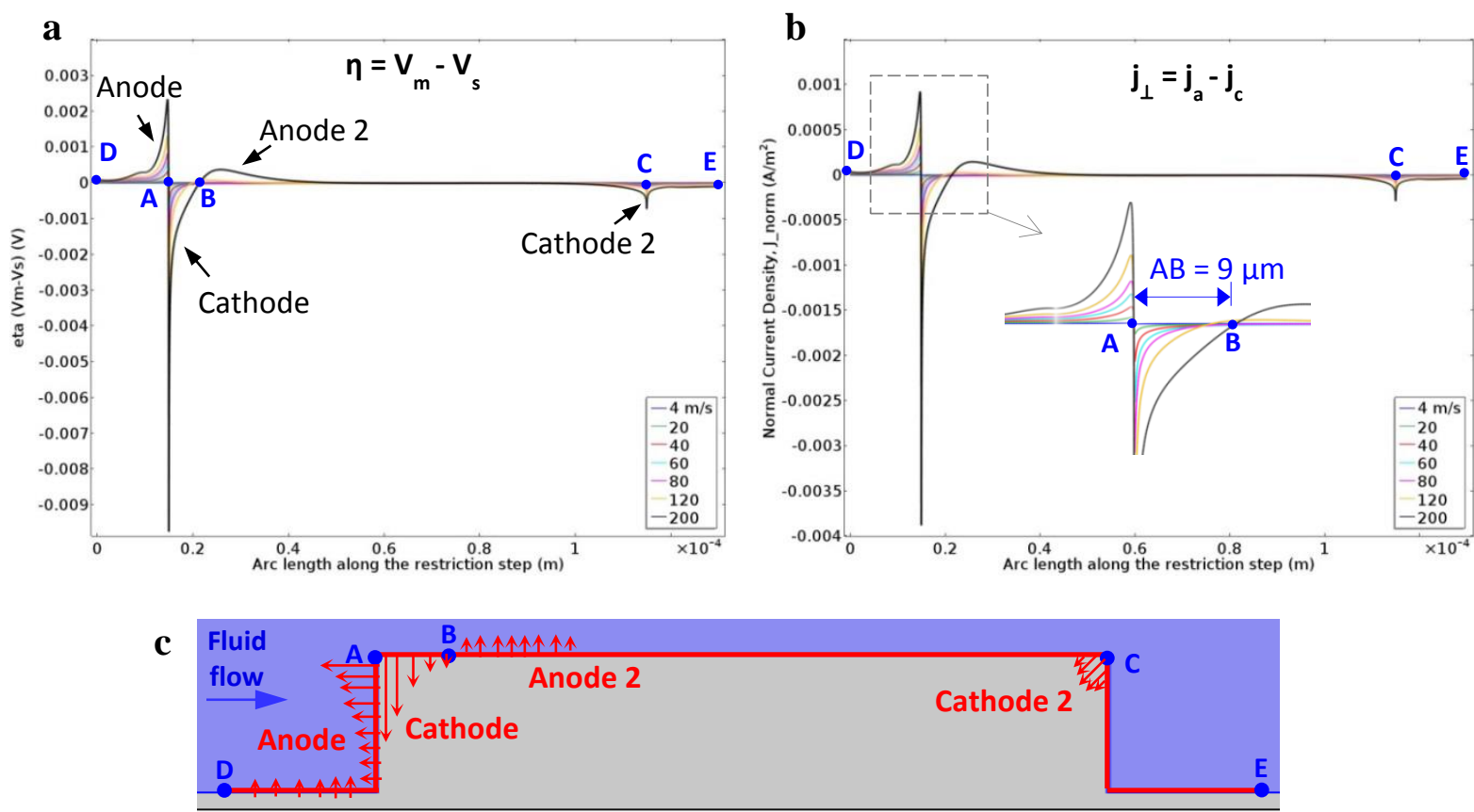

Fig. 6 a Overpotential along the restriction step b Normal current density c Current path between the solution and metal

\subsection{Deposition Propagation - Stage 2}

A 'bump' with $1 \mu \mathrm{m}$ radius was added at the inlet corner of the restriction to simulate the initial deposit, which has the same metal material for simplification in the present model. The resulting behaviour of the fluid flow and electric current is shown in Fig. 7 which is similar to that of stage 1 in

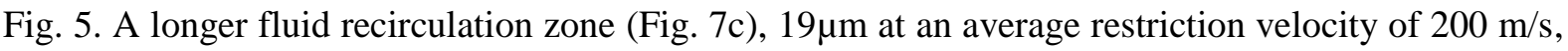
was found due to the greater geometric disturbance of the simulated deposit. The size of the fluid recirculation zone controls the size of the electric recirculation zone, giving the same size of the upstream fluid flow and streaming current (Fig. 7a). Similarly, the upstream streaming current joined the streaming current from the FFS conducting into the metal generating the strongest current loop, loop 1, which is located at the top of the simulated deposit. This may explain the growth of the initial deposit - initiating at the corner and continuing to grow into a deposit. Two additional big loops extending to the restriction outlet were found.
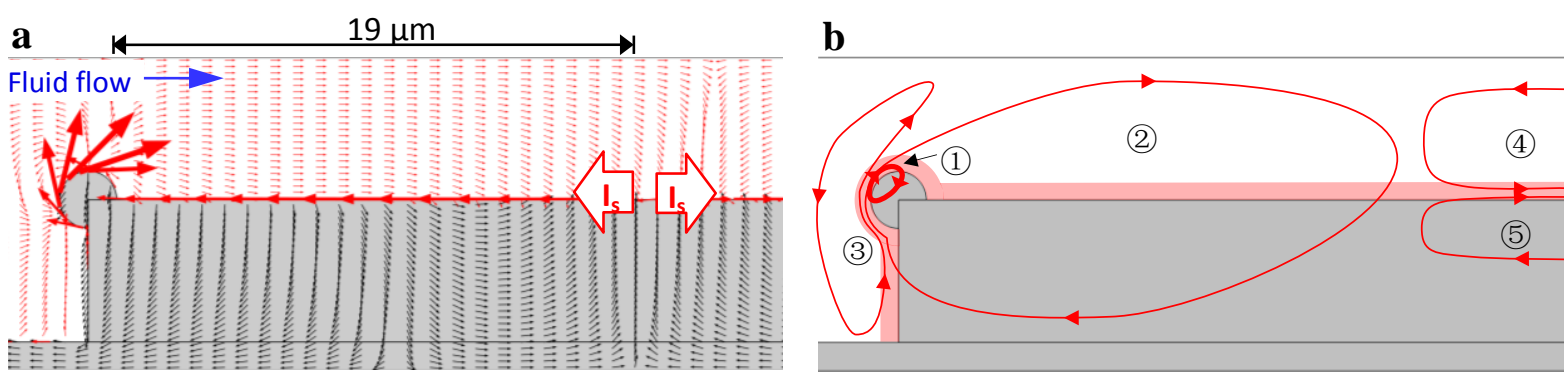

c

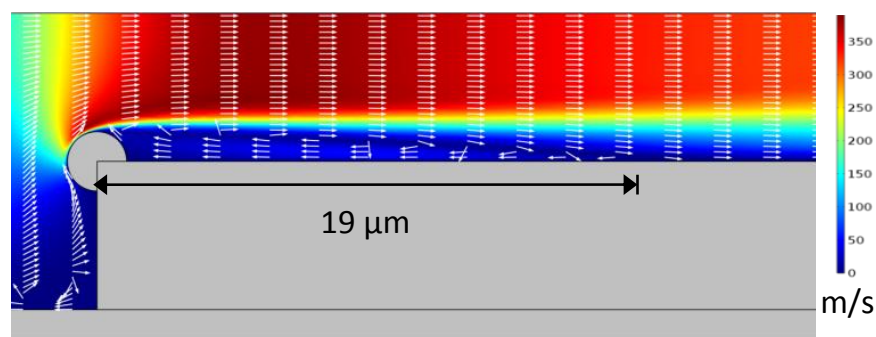

Fig. 7 Current and fluid flow at stage 2 a Current in solution and metal b Schematic current path $\mathbf{c}$ Fluid flow velocity field showing a $19 \mu \mathrm{m}$ recirculation zone adjacent to the inlet, $\overline{\boldsymbol{v}}_{r e}=200 \mathrm{~m} / \mathrm{s}$ 


\subsection{Deposition Propagation - Stage 3}

A second 'bump' with $1 \mu \mathrm{m}$ radius was then placed $19 \mu \mathrm{m}$ away from the first simulated deposit inside the restriction to simulate the second deposit, where the second anode was located at stage 2 , as shown in Fig. 8a. In the area between the restriction inlet and the front of the second deposit, similar characteristics of the fluid and electric current as stage 2 were observed.

Another recirculation zone with smaller size, $10 \mu \mathrm{m}$ at an average restriction velocity of $200 \mathrm{~m} / \mathrm{s}$ in Fig. 8d, was found following the second deposit, which brings the streaming current upstream as shown in Fig. 8a. The upstream streaming current joining the streaming current from the front of the second deposit was mainly conducted into the metal. Extra loops were found around the second deposit showing anodic and cathodic behaviour in the front and at the back, respectively, as shown in Fig. $8 \mathrm{~b}$. The densest current, loop 1 in Fig. $8 \mathrm{c}$, is located at the top of the second simulated deposit which is similar to the first simulated deposit. Loop 2 shows the edge of the current between the metal and solution in this region. The remaining of the streaming current flowing downstream generated two further loops extending to the end of the restriction.

$\mathbf{a}$

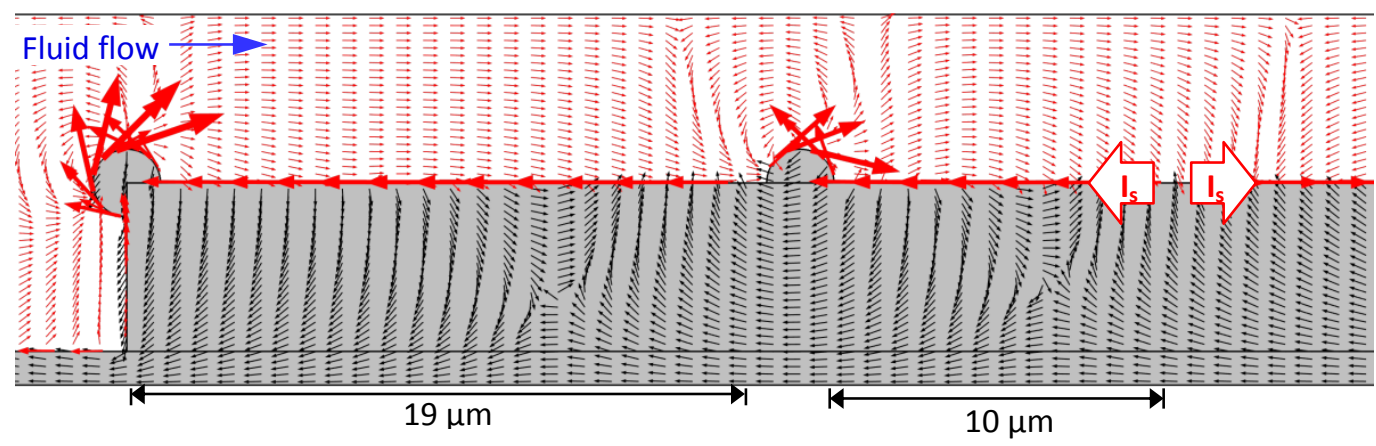

b

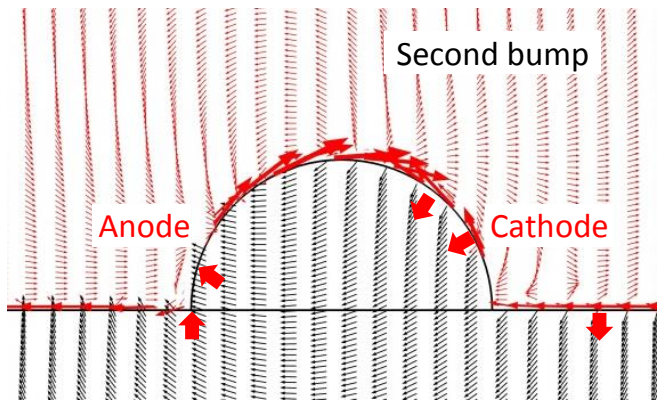

c

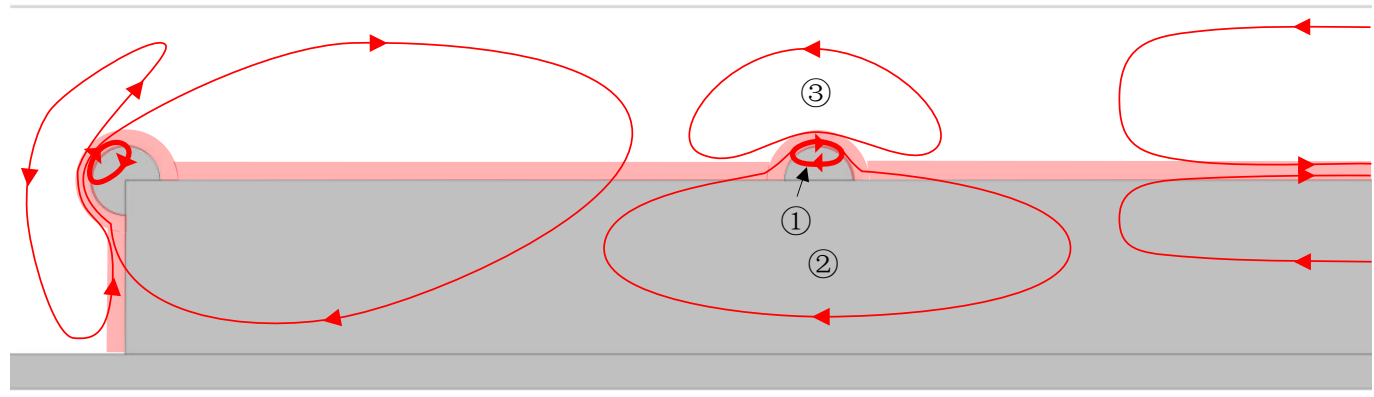




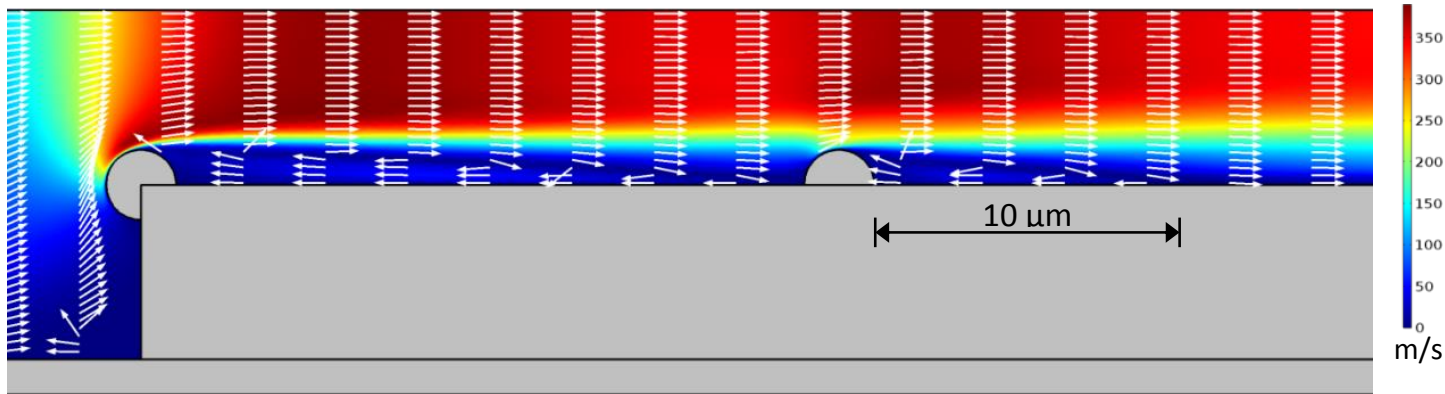

Fig. 8 Current and fluid flow at stage 3 a Current in solution and metal $\mathbf{b}$ Current details around the second simulated deposit c Schematic current path d Fluid flow velocity field showing a $10 \mu \mathrm{m}$ recirculation zone following the second deposit, $\overline{\boldsymbol{v}}_{r e}=$ $200 \mathrm{~m} / \mathrm{s}$

\subsection{Comparison between Stage 2 and 3}

Normal current density and current path of stage 2 and 3 at different average restriction flow velocities are shown in Fig. 9. For stage 2, the anodic region is located at the FFS and the front face of the initial deposit with current flowing from metal to solution and a cathodic region from the back of the initial deposit to point B with current flowing from solution to metal. A second anode was also found adjacent to the first cathode. This shows a similar electric current phenomenon as observed at stage 1 .

For stage 3, an extra anode (Anode 2) and cathode (Cathode 2) were found around the second deposit as shown in Fig. 9c and d. A third anode (Anode 3) was found following the second cathode, which means a third deposit should be located in this area. The rest of the area along the restriction step showed a similar behaviour as observed at stage 2 .

From stage 2 to 3, the location of a third deposit (Anode 3) was found after the second deposit 'formed'. This means that an extra anode (thus an extra deposit) always appears after a previous deposit generates. We call this phenomenon deposition propagation. Anode 2 and 3 simulate the deposit ripples inside that are observed in actual restriction in plants.
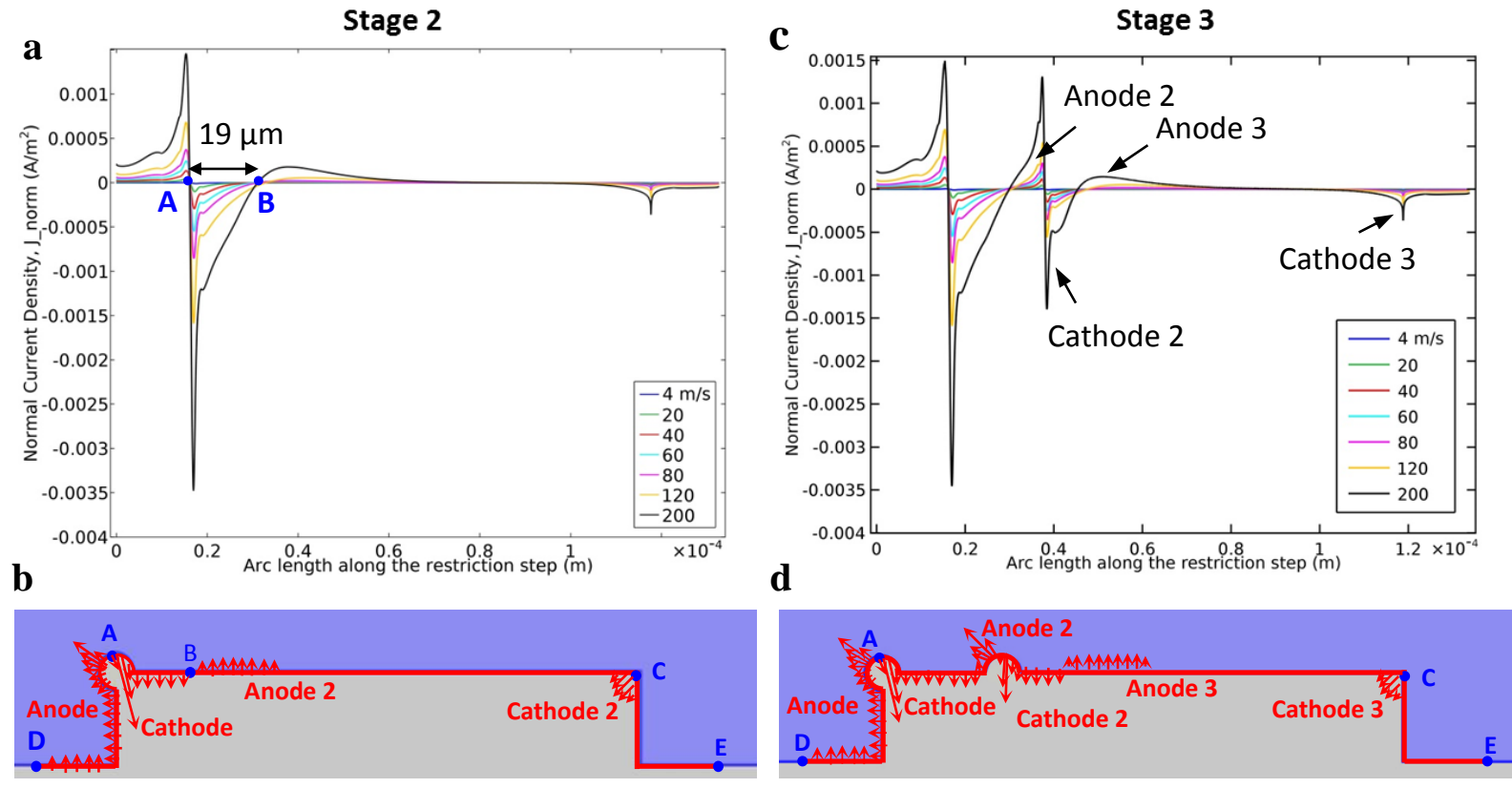

Fig. 9 a Normal current density along the restriction step at stage 2 b Current path between the solution and metal at stage 2 c Normal current density along the restriction step at stage $3 \mathbf{d}$ Current path between the solution and metal at stage 3 


\section{Conclusions}

An electric model describing initiation and propagation of CRUD deposition in geometric restrictions was built and discussed in this paper. The anodic and cathodic characteristics along the restriction step surface were investigated. It was found that the recirculating fluid flow over surfaces following sharp disturbances (i.e. restrictions) gives rise to coupled anodic and cathodic regions when a charged Electrical Double Layer is present. An anodic region was found at the front facing step of the restriction followed by a cathodic region. A coupled second anode was adjacent to the cathode. After an additional simulated deposit was introduced inside the restriction at the locations of the anodic currents (e.g. from stage 2 to stage 3), an extra couple of cathode and anode was found within a fluid flow recirculation zone surrounding the simulated deposit. The length along the wall surface and the current density value of anode and cathode both increase with the increasing average restriction fluid flow velocities, which indicates that larger size and mass of deposits may be found at the anodic area at higher velocity in a certain velocity range.

Where the solution resistivity $\left(\rho_{s}\right)$ is high compared to the polarization resistance of the interface $\left(R_{p o l}\right)$, significant wall currents linking the anodic and cathodic regions passing through the solution/metal interface are predicted. Where CRUD deposition rate is assumed to be accelerated in anodically polarized regions, then a pattern of initiation and sequential propagation of deposits is predicted, which matches the experimentally observed build up on the external face of a step, and the rippled surfaces inside the flow restriction.

To the purpose of maximising the EDL effect on the deposition process, micrometre size geometry was used in this model. This should not affect the kinetics when it scales up to millimetre size in the future work. Restriction diameter effect and more details of velocity effect on the oxide formation will also be studied in the future work. 


\section{Reference}

1 Roy A. Castelli, Nuclear Corrosion Modelling (Oxford: Butterworth-Heinemann, an imprint of Elsevier, 2009), xi - xvii.

2 EPRI, "Characterization of PWR Steam Generator Deposits," (Report EPRI TR-106048, Dominion Engineering, INC., McLean, Virginia, 1996).

3 IAEA, "Current Trends in Nuclear Fuel for Power Reactors - NTR Supplement" (Information document from $51^{\text {st }}$ IAEA General Conference, Austria Center Vienna, Bruno-Kreisky-Platz, Vienna, 17 September 2007), 11.

4 M. Guillodo et al., "Formation of Deposits in HT Water under High Velocity Conditions : a Parametric Study" (Paper presented at the Water Chemistry of Nuclear Reactor Systems Conference, San Francisco, California, 2004), 1941-1949.

5 S. Odar and P. Rudling, "Crud in PWR / VVER coolant Volume I - Sources, Transportation in Coolant, Fuel Deposition and Radiation Build-up” (Report LCC10 STR, ANT International, 2014).

6 M. Vepsalainen and T. Saario, "Magnetite dissolution and deposition in NPP secondary circuit" (Report VTT-R-09735-10, VTT, 2010).

7 C. Brun et al., "Investigation on the Relation between Pressure Drops and Fluid Chemical Treatment" (Paper presented at the Water Chemistry of Nuclear Reactor Systems Conference, Avignon, France, 2002).

8 M. Guillodo et al., "Singular Deposit Formation in PWR due to Electrokinetic Phenomena Application to SG Clogging" (Paper presented at the $6^{\text {th }}$ CNS International Steam Generator Conference, Toronto, Ontario, Canada, 2009).

9 J. Robertson, "Corrosion and Deposition Due to Electrokinetic Currents" (Report TPRD/L/3030/R86, CEGB, 1986).

10 I. S. Woolsey et al., "Occurrence and Prevention of Enhanced Oxide Deposition in Boiler Flow Control Orifices" (Paper presented at the Water Chemistry of Nuclear Reactor Systems 5, Bournemouth, UK, 1989).

11 F. Scenini et al., "Electro deposition of CRUD” (Report R115529, University of Manchester, 2014).

12 F. Scenini et al., "Investigation of the Role of Electrokinetic Effects in Corrosion Deposit Formation," Corros. Sci., 87(2014), 71-79.

13 F. Scenini et al., "Electrochemical and Direct Build Up Measurements of Oxide Deposition in Accelerated Flow" (Paper presented at the $20^{\text {th }}$ NPC Conference, Brighton, UK, 2016).

14 M. Guillodo et al., "Experimental and numerical study of deposit formation in secondary side SG TSP by electrokinetic approach" (Paper presented at the Nuclear Plant Chemistry Conference, Paris, France, 2012), 1-14.

15 C. W. Turner and M. Godin, "Mechanisms of magnetite deposition in pressurized boiling and nonboiling water," (Report AECL-11046, Atomic Energy of Canada Limited Research, 1994).

16 C. Henry, J. P. Minier, and G. Lefèvre, "Towards a description of particulate fouling: from single particle deposition to clogging," Adv. Colloid Interface Sci., 185-186 (2012), 34-76.

17 C. Brett and M. Brett, "Electrochemistry - Principles, Methods and Applications" (Oxford, UK: Oxford University Press, 1993), 39 - 68.

18 J. Bockris and A. Reddy, “Modern Electrochemistry 2” (New York, NY: Plenum Press, 1977), 718-790.

19 D. Pletcher, "A First Course in Electrode Process, 2nd edition" (Cambridge: The Royal Society of Chemistry, 2009), 1-47.

20 A. Banks, A. Powell, and L. Pegg, "University of Birmingham, Continuum Blue, Rolls-Royce COMSOL Modelling" (A talk presented in a meeting in University of Birmingham, 11 December 2014).

21 D. Li, "Electro-viscous effects on pressure-driven liquid flow in microchannels," Colloids Surfaces A Physicochem. Eng. Asp., 195 (2001), 35-57.

22 K. Bohinc, V. Kralj-Iglič, and A. Iglič, "Thickness of electrical double layer. Effect of ion size," Electrochim. Acta, 46 (2001), 3033-3040.

23 E. Bardal, “Corrosion and Protection” (USA: Springer-Verlag London, 2004), 35 - 51. 